\title{
FILM LANGUAGE AND KAADU (A Critical Analysis of Girish Karnad's Kaadu, (The Forest))
}

\author{
Mahantha D.U. \\ Research Scholar, \\ Department of English, \\ Kuvempu University, \\ Shankaraghatta, \\ Shimoga(Dist). \\ India \\ Under the guidance of; \\ Prof. Rajendra Chenni \\ Dept. of P.G Studies and \\ Research in English, \\ Kuvempu University, \\ Shankaraghatta, \\ Shivamogga (Dist)-577451.
}

Article DOI: https://doi.org/10.36713/epra2290

\begin{abstract}
This article spreads light on how successfully the masterly writing of Shrikrishna Alanahalli in short story Kaadu has emerged in the form of Cinema under the direction of Girish Karnad ${ }^{i i}$ and what are the cinematic elements we can find in the story. The writer has placidly told how at the same time as seeing their land lords turning monstrous for their egotistical means, the innocent village people become a part of it without unknowingly. Most importantly, a unique narrative technique of narrating these sequences with the view point of a small boy has been used. Adaption of this unique technique in the medium of cinema is a challenging task. Nevertheless, by means of the effective dialogues and the meaningful background music, photography and so on and the best acting given by the artists, the director has emerged successful in depicting the monstrous face of human beings. The article is an endeavour to understand the cinematic language, possibility and artistic nature of cinema.
\end{abstract}

KEY WORDS: Art cinema, Film language, Point of view, Caste discrimination, Class Conflict, Male domination,

\section{INTRODUCTION}

Cinema is a huge art medium and a commercial industry as well. Cinema has turned a mere commodity from an art work as it has transformed along its growth as an art form to massive commercial industry. The low-budget cinemas produced merely with the intention of making money have lead to a situation where it is hard to accept that "Cinema is an art". At this juncture, the art cinemaiii brought a ray of hope among the people who have deep inclination for films. The art film directors gave a new direction to the film media as they tried to introduce 'cinematic language', 'structure', 'artistic and aesthetic elements' in cinema. Even the audience have developed among themselves an interest towards such films and also considered the medium of film. The first Kannada art movie Samskara ${ }^{i v}$ was screened on silver screen in 1967. Girish Karnad who wrote the script and dialogues for Samskara movie and acted in the lead role, has his own influence in the Kannada art movies. Kaadu which hit the silver screen in 1977 is the first cinema which was directed independently by Girish Karnad. 


\section{KAADU (The Forest)}

The friction enkindled between the leaders of adjacent villages in the matters related to land takes the form of caste differences and a matter of pride, with women, going to the extent of depriving one of their access to food, poisoning the dumb innocent animals, men raping the innocent girls resulting in killing the innocents. Eventually, a holocaust makes the whole village turn into a graveyard. The savagery of human nature is unravelled in Kaadu written by Shrikrishna Alanahalli. There is a skilful use of language in the short story Kaadu. The inhuman activities like exploiting the weaker sections of people and killing them for some caste and gender prejudices and in order to keep hold to the pride of masculine power has been brought out deeply in the writing of short story. While reading this barbarity seen among the innocent villagers, the readers do not feel touched. Similar opinion was seen in the then Newspaper article/review about this novel, that though the catastrophes in the novel similar to those seen in movies, moves the readers, it seems they are ephemeral"

The major short coming here is that the novel does not have a strong base. When a reader goes deep down into the insight of the novel penetrating through all the shattering catastrophic elements in the writing of the Kaadu, there is an emptiness. [Alanahalli, 2010, p. 107.]

Though all these opinions, reviews are not invalid, the readers have to consider this not as a negative element of the novel but as that which the writer has done this purposefully. It should be understood that the narrative technique of the novel has distanced itself from the emotional agitations. The novel Kaadu by Krishna Alanahalli's been narrated by the lead role, a small boy by name Kitti. The innocent Kitti's understanding cannot discern the atrocity seen in his surroundings. It is for this reason that the entire novel has been depicted with no emotional agitations.

"Kitti's innocence has bestowed the Director with many privileges. The narrator has no insistence of questioning or analyzing anything going beyond the narration of circumstances. The narration is posed with no essentials to see anything in friction but to depict things as they are. Thus the novel does not urge the reader to look at the work with a certain approach. For instance; we can look at the point that the narrator does not take to depict with any specific approach about the Chavadi incident wherein Kencha is thrashed for raising his voice against Chandregowda and about the advising villagers who are faulty at heart. This could be achieved only for the reason that the whole novel is viewed through Kitti's perspective". [Shanbhag, 2010, p. 9.]
The short story Kaadu has skilfully used language. The writer throws light upon the other facet of village life. The writing goes deep into the material descriminities of a village life like caste, gender discrimination, patriarchal value system which are the widespread elements of a village life and the atrocities, exploitation, monstrous tendencies of killing one another and giving it a colour of prestige and power.

Viveka Shanbhagv, analyses that inspite of the fact that the writer has deliberately imposed selflimitation in not questioning anything and criticizing anything but just depicting the circumstances as they are, the reader is promoted by such a narrative technique to interpret each circumstance of the short story with multiple dimensions as the author Alanahalli has put forth the experiences, with their complete, complex nature and with the usage of incisive language.

All the above mentioned features which shall have to be essentially present in an artistic movie are evolved in the plot of Kaadu and the plot of Kaadu has multidimensional approach. These factors might have promoted Girish Karnad to present this story in the medium of cinema.

As Karnad himself has told in his autobiography, in this narrative, Alanahalli has poured the familiar experiences of his village life and delineated the violence in village life, the mindless hold of customs in front of which the women were treated animalistic. All these elements are implicit in the narrative. Girish Karnad has opined that this 'Krowrya' had its own sightful approach and a thematic unity. (The original title of the novel was 'Krowrya', but the Director Karnad has changed it to Kaadu thereby implicitly suggesting in the title the inherent 'Krowrya' in the story). [Karnad, 2011, p. 277]

And, it can be viewed that in view of all this the short story Kaadu has been transformed as it is into the form of movie. We can even see that Karnad has shown the whole story with the point of view of Kitti himself as is in the original writing and it is for this reason that the film also moves forward placidly and it appears that keeping in mind the technical aspects the director has not given a serious attempt at analyzing things going beyond the circumstances narrated in the story. But, the medium of art movie needs it to be interpreted beyond the circumstances. Even though the director has presented the movie with the narration of Kitti as is in the original writing, the sequences in the film should be enabled in a way of voicing beyond just narration of things as they are. This is interms of the fact that there is a difference between a story and a cinema. At this point, the opinion of Anantamurthyvi can be referred; However good a cinema is made, but the story writer would feel that there is something lacking in the movie 
made based on his story. A movie depicts even more poise the story that which is shown in the original story nevertheless.

It's true that a cinema would depict with even more poise the narration in the story. The beauty of the elements which are veiled in narration but shine out in the skilful use of language would be lost in the process of film making. Anantamurthy, 2012, p.284.]

Kaadu is a challenging subject for a movie as it has involved in it the quality of veiling many elements of the story and empowering them in its skilful use of language making them still visible to the readers. The novel Kaadu by Alanahalli, speaks implicitly about many issues. The novel spreads light on several issues like gender discrimination, male domination, feudalism etc., This is why, a director needs to be acutely observant while adopting such a literary work into the form of cinema. If we have to analyze some of the matters which leads to a discussion in several sequences in the novel;

\section{EXTRAMARITAL RELATIONSHIP AND ITS DEPICTION}

In the novel, the extramarital affair becomes adultery, debauchery and an unceremonious act in connection with a woman. If a woman is seen doing this, she will be seen as someone who threw the dignity of not only of her house and clan but also of the whole village into dust. Such characters have to surrender to the NYAYA(?!) judgments given by the panchayats ${ }^{\mathrm{vii}}$ which are under the control of men, without questioning them. Dejected by the public who speak bitterly of their personal life, they step forward to take the extreme steps of going away from the village, committing suicide. The characters Kalyani, Savitramma wife of Poojarappa are some example for this in the novel.

On the other hand, these extra marital affairs in connection with men get depicted in a different way altogether. Chandregowda, though married, has a relationship with Basakka of Hosur and the whole village is aware of this fact. No one questions Chandrappa about this matter. Even his wife Kamalavva has no right to question him. She is so helpless that she can only complain about this (not publicly) to god.

Girish Karnad has made a good attempt in this direction. Cinema begins with the close-up scene of 'Jiraki Chappaliviii', Gowda steps out of his home wearing Jiraki Chappali holding a battery. Kamalamma helplessly looks at the way her husband went and Kitti her elder brother's son looks innocently at her interrogatively as he does not understand what her pain is. This is the beginning scene of the film. The Chappali (footwear) has been used as a trope ${ }^{\mathrm{ix}}$ to denote the relation of a man with the outer world. The sound heard from the footwear when he is going indicates the male ego. Thus, this scene effectively depicts on the one hand the male ego and the connection of Chandregowda with the outer world and on the other the helplessness of his wife and the state of puzzled Kitti.

Another point to be noted here, the author seems to stand in favor of Chandregowda. The writer has justified the extramarital relationship of Chandregowda through approaching it with another dimension or giving an explanation that Kamali could not give him children. The other point that the audience should observe in the movie is that Chandregowda considers his extra marital relationship as a symbol of his manhood. He has the odious nature of showcasing his male ego or manhood in this way. A sequence in the film is thus:

When the relationship between Chandregowda and Shivaganga had completely deteriorated, Basakka his mistress sends him a message though a servant telling him not to come to her home for one week as it is dangerous for him to wander alone. But, Chandregowda takes it as a question of his courage and pride and replies that he will come to her house the following day and she should keep the bed ready, he will see to whoever that comes in his way. Saying this he scoffs. Listening to his words, Kamalamma closes her eyes and takes a deep sigh with pain. In what way this behaviour of Chandrappa who speaks in front of his own wife about having carnal pleasures with another woman, is to be understood? This makes the audience ponder over his shamelessness.

The same thing which becomes adultery, debauchery relating to women, is a symbol of manhood, pride and courage relating to men. Such social notions are based on which logical and moral values? Chandregowda stands as an unquestionable person for the fact that he is a prominent person in the village and a big landlord. Chandregowda can use Basakka with the use of his money, power and social status. Whereas, Kencha's seduction of Devi enticing her with a saree becomes offence. When Basakka gets lured by money, the moral and ethical values do not strike her as he is having a relationship with a big landlord, but when Devi is enticed just for a Saree, the moral and ethical code of the society holds her as an offender, a debauchee because both Dyavi and Kencha are of lower status. This is the dilemma in the social values.

If we look at the role played by caste in such matters; Kencha not just forces Dyavi but also tries to entice her offering her certain things. Behind his shamelessness, there are factors like Devi's poverty, her husband's helplessness and incompetency and also the support he has from his master like Shivaganga and 
above all Devi's lower caste. Due to these things, this matter does not become a considerable issue. It also seems that he is fearless thinking that nobody can do anything to him.

The Panchayati Katte scene has emerged very effectively in the cinema. Frames in this scene are good examples for mise-en-scene ${ }^{x}$ technique. In the Panchayati Katte, all those who are sitting in the 'Nyaya Peeta' and those who have come to panchayath are all men (except Devi who is standing in the place for accused). The women of the village have kept their ear to the doors, veranda and windows of their houses and eyes towards Panchayati Katte and are eagerly waiting to hear from the proceedings in the Nyaya peeta. As soon as the trial begins, Chandregowda thrashes Dyavi who is not in a situation to utter a single word, infront of all the villagers including her husband Subba.

When Shivaganga speaks on behalf of Kencha, Chandregowda asks him is Kencha a paramour to his wife that he is speaking in favor of him. Retorting to Chandregowda's abuse, Shivaninga raises the topic of his illicit relationship with Basakka in front of the whole village. Offended by this, he fumes his anger on Kencha by thrashing him black and blue. This sequence of Panchayth effectively picturises the status that a woman is given in the society and atrocious nature of men and how the women belonging to lower caste are treated as less than an animal. We can see another instance which shows how helpless women are in this system; when Kitti is seen crying on remembering his pet dog Monna, Kamalamma asks him would he cry in the same way on her death like the way he is crying on the death of his pet. This question suggests her insecured feelings towards life; this question makes the audience think whether Kamalamma is bothered thinking whom does she have in her life? Her father's house is no more her house; her husband now has a mistress discarding Kamalamma, moreover she has no children; One day Kitti will also go back to his home leaving Kamalamma. Thus, her position is no less than that dog. But, the director has overlooked the possibility of depicting the pain, helplessness and insecurities of Kamalamma even more effectively. It seems that the director is attempting to show everything only through the dialogues as is the case in previously discussed scene. It can be noticed that the cinematic language has not been used effectively. The dialogue written by Shrikrishna Alanahalli has made a tremendous contribution to the film.

To state one more sequence of similar nature from the movie, Singappa, Kalyani's husband has burnt her skin on thighs for losing her ear rings in the similar way as the animals would be given a burn on their skin. When Kalyani comes to Kamalamma, suffering from pain, the later treats her wound consoling her. At the same time Chandregowda turns up there and asks what happened. But, when Kamalamma proceeds to tell about what has brother-in-law has done to Kalyani, he cuts her words and asks her to serve dinner as he has to go to the play and look after the arrangements. This reaction of Chandregowda to Kalyani's pain, shows how the whole generation of men reacts to the pain and suffering of women and her exploitation in the hands of this patriarchal society.

The director has brought in the scenes of the play 'Prachanda Ravana' enacted in the film. In that scene, Ravana owes to avenge the Rama brothers for insulting his sister Soorpanaka. Rama and Lakshmana deform the face of Soorpanaka for expressing her love and in order to avenge this heinous act of Rama brothers, the great scholar Ravana kidnaps Sita which is even bitter. Ravana punishes Rama's wife for the misconduct of Rama and Lakshmana. Here, neither Sita nor Soorpanaka are at fault. Both of them are innocents but subjected to humility under the patriarchal values. Thus, this victimization of women for the atrocities of men has come down since ages and this fact has been depicted very effectively in this scene and it can be said that thereby the director has used the possibilities offered in medium of cinema very effectively.

At the end of the film, the 'village' brings fear in Kitti as he goes on witnessing a series of tragic incidents like Kamalamma's death, the carnage in Hosur and the police arresting almost all of the villager and police seen everywhere in the village. Puzzled with the situations he goes to 'Kaadu' (forest). There, he feels that someone gave him a call. He think its a call of an ominous bird which can bring death and feels scared to reply to the call and sits there in panic. The assumption that listening to the cry of certain bird would bring death to someone who listens it crying. He listens to the cry of such a bird and panics. Similarly, the sad end of his pet Monna and his aunt Kamalamma creates havoc in his mind. The director has tried at constructing the way in which the violence that is happening in Kitti's surrounding enters Kitti's mind and the dilemma he faces about the relationship between society and the individuals and the form it takes in Kitti's mind Ashish and Paul has analysed the status of Kitti's mind thus:

"The boy cannot distinguish the specifically man made violence that surrounds him from the more primeval threats presented by the dense forest which, according to a legend, contains a killer bird that calls out its victims by name" [Rajadhyaksha and Willman, 1999, p. 418.]

In the same book, further he has opined that Karnad's Kaadu and Benagal's Ankur placed both film 
makers "squarely within New Indian Cinema's ruralism”. [Rajadhyaksha and Willman, 1999, p.411]

Kaadu movie has given a great contribution to the history of the art movie in Kannada. G.S. Nataraj son of G.V. Shivananda has given good acting and even got national award as best child actor for his acting in this film.

The efficient experiment in language in the movie has acted complementary to the best acting given by Amarish Puri and Lokesh in the film. Art direction and music composition by B.V. Karanth ${ }^{\mathrm{xi}}$ has played an important role in the film. The use of local tunes in the background music has enhanced effectively the shade of fatal incidents occurred in the village. It can be said that it created a new genre.

Karnad says this about the photography of Govind Nihalanixii: Govind Nihalani has picturised the elaborative Okulixiii scene extraordinarily owing to this background in feature films and through the lighting effect along has given the tragic effects to the movie which had black and white scenes as in European Noir Films. Since eighty percent of the movie is shot at night or within the house, this kind of variation in play of lighting effects has brought its own polish to the movie. [Karnad, 2011, p. 281.]

The original writing which was titled as Krowrya has been changed as Kaadu by the director to keep it implicit. Though the title has been used suggestive of broader meanings he has not thrown light on several issues which could be conveyed as implicitly as the title.

\section{End Notes}

${ }^{i}$ Srikrishna Alanahalli was a Kannada novelist and poet. He became popular for his novels Kaadu (1972), Parasangada Gendethimma (1978) and Bhujangayyana Dasavataragalu(1982), all of his novels were adapted into films.

${ }^{i i}$ Girish Karnad was an Indian actor, film director, Kannada writer, playwright who predominantly worked in South Indian cinema and Bollywood.

iii The term "art cinema" is one of the most familiar in film studies, marking out simultaneously specific filmmakers, specific films, specific kinds of cinemas, and, for some writers, specific kinds

${ }^{i v}$ Samskara is a 1970 Indian Kannada-language film written by $U$. R. Ananthamurthy based on his eponymous novel, and directed and produced by Pattabhirama Reddy.

${ }^{v}$ Vivek Shanbhag is a story writer, novelist and playwright in Kannada. He is the author of eight works of fiction and two plays, all of which have been published in Kannada.

${ }^{v i} U$. R. Ananthamurthy was an Indian contemporary writer and critic in the Kannada language. He is considered as one of the pioneers of the Navya movement. He is the sixth writer to be honored with the Jnanpith Awardfor the Kannada language.

vii Panchayat is a village council in India.

viii It's a foot wear made up of leather.

${ }^{i x}$ Trope is a word used in an literal sense to create a powerful image.

${ }^{x}$ Mise-en-scene is the arrangement of the scenery, props, etc. on the stage of a theatrical production or on the set of a film.

${ }^{x i}$ B.V. Karanth was a noted film and theatre personality from India. Throughout his life he was director, actor and musician of modern Indian theatre both in Kannada as well as Hindi.

xii Govind Nihalani is an Indian film director, cinematographer, screenwriter and producer, known for his works in Hindi cinema.

xiii Okuli is a Hindu spring festival, bonfires are lit and coloured water thrown on celebrants.

\section{BIBLIOGRAPHY}

1. Alanahalli, Shreekrishna. Kaadu, Bharathi Prakashana, 2010.

2. Anantamurthy, U.R. and anchr. Tejashree, Ja.Na., Suragi, Akshara Prakashana, 2012.

3. Eisenstein, Sergei. The Film Form, A Harvest Book, 1977.

4. Kaadu, Dir. Girish Karnad, L N Combines.1973.

5. Karnad, Girish. Aadadata Aayushya, Manohara Grantha Mala, 2011.

6. Kuhn,Annette. and Westwell,Guy. Dictionary of Film Studies, Oxford University Press, 2012.

7. Monaco, James. How to Read a Film, Oxford University Press, 2009.

8. Rajadhyaksha, Ashish. and Willman, Paul. Encyclopaedia of Indian Cinema, Oxford University Press, 1998.

9. Samskara, Dir. Pattabhi Rami Reddi, Ram Manohar Chitra, 1970.

10. Shanbhag, Viveka. Shri Krishna Alanahalli Vaachike, NudiPustaka, 2010.

11. Tabbaliyu Neenade Magane, Dir. Girish Karnad and B.V. Karanth, Chandulal Jain, 2007.

12. Vamsha Vruksha, Dir. B.V. Karanth and Girish Karnad, AnanthaLakshmi Films, 2008. 